\title{
MIMESIS E RITUAL: Bases do Agir Social, Funções e Fenômenos Sociais e Culturais na Educação
}

\author{
Karina Augusta Limonta Vieira ${ }^{1}$
}

\begin{abstract}
RESUMO
Esse artigo tem como objetivo analisar as bases miméticas do agir social e apropriação de mundo por meio do ritual, as funções do ritual na educação e discutir sobre os fenômenos sociais e culturais na educação. Quais são as bases miméticas do agir social e apropriação de mundo por meio do ritual? Quais são as funções do ritual na educação? Como se constitui a relação do processo mimético com o ritual enquanto fenômenos da mimesis social e cultural? Os referenciais teóricos sobre mimesis e ritual têm como abordagens a antropologia e a antropologia educacional alemã. O método utilizado nesta pesquisa é análise de conteúdo hermenêutica, e o trabalho consiste em analisar/refletir o sentido geral do material textual das obras selecionadas. Os resultados da análise expõem que as bases miméticas do agir social levam à apropriação do mundo e constituição do sujeito, tendo o ritual como constituição do sujeito e noção de pertencimento à comunidade, e as funções do ritual na educação envolvem: a) relações sociais, realidade social, relações de poder e contexto; b) performance e práticas corporais; c) tempo e espaço, repetição e sequencialidade; d) alteridade, sincronicidade, diacronia e mudanças sociais e culturais.

Palavras-chave: Mimesis. Ritual. Educação.
\end{abstract}

\section{MIMESIS AND RITUAL: \\ SOCIAL ACTING FOUNDATIONS, SOCIAL AND CULTURA FUNCTIONS AND PHENOMENA IN EDUCATION}

\section{ABSTRACT}

This paper aims to analyse mimetic foundations of social acting and appropriation of world through ritual, ritual functions in education and to discuss on social and cultural phenomena in education. Which are mimetic foundations of social acting and appropriation of world through ritual? Which are ritual functions in education? How does relation of mimetic process to ritual as phenomena of social and cultural mimesis establish? The theoretical framework on mimesis and ritual is based on anthropological and German educational anthropology approaches. The method to analyse is hermeneutic content analysis, i.e., to analyse/meditate on choosen textual material and to perform an analysis of general sense of texts. The results point out that mimetic foundations of social acting lead to, through ritual, appropriation of world and establishment of individual. The ritual functions involve: a) social relations, social reality, power relations and context; b) performance and bodily practices; c) time and space, repetition and sequentiality; d) alterity, synchronicity, diachrony and social and cultural changes.

Keywords: Mimesis. Ritual. Education.

RECEBIDO EM: 16/12/2019

ACEITO EM: $16 / 6 / 2020$

\footnotetext{
${ }_{1}$ Universidade do Estado de Minas Gerais. Av. Juca Stockler, 1130, Passos/MG, Brasil. CEP: 37900-106. Membro do Centro Interdisciplinar de Antropologia Histórica (FU/Berlin, Alemanha). http://lattes.cnpq.br/0217091409131974. https://orcid.org/0000-0002-4837-8374. kalimonta@gmail.com
} 
Mimesis e ritual possuem uma relação na qual os rituais são fenômenos da mimesis social que moldam as transições entre os campos da socialização e das instituições educacionais. Este artigo tem como objetivo analisar as bases miméticas do agir social e apropriação de mundo por intermédio do ritual, as funções do ritual na educação e discutir sobre os fenômenos sociais e culturais na educação. Para alcançar tal objetivo são necessárias três questões para refletir sobre mimesis e ritual: Quais são as bases miméticas do agir social e apropriação de mundo por meio do ritual? Quais são as funções do ritual na educação? Como se constitui a relação do processo mimético com o ritual enquanto fenômenos da mimesis social e cultural? O referencial teórico sobre mimesis e ritual tem como abordagem a antropologia e a antropologia educacional alemã. Essa teoria reconhece o ser humano, a sua educação e as suas condições de educação em sua formação, socialização, educação, aprendizagem e ensino específicos de cada diferente cultura em sua historicidade, assim como leva em consideração os gestos, a performance e ação do ser humano no mundo.

Este artigo é composto pelas seguintes partes: "Mimesis: a historicidade do processo mimético", "Ritual: conceituação", "A mimesis e a educação", "Os rituais na educação", "Metodologia", "Análise e resultados: 'as bases miméticas do agir social e apropriação de mundo por meio do ritual' e 'as funções do ritual na educação', "Discussão: fenômenos sociais e culturais na educação", "Considerações finais" e "Referências".

O método utilizado nesta pesquisa é a análise de conteúdo hermenêutica, e o trabalho consiste em analisar, apresentar e refletir o material textual das obras selecionadas. De todo o material, foi feita a análise do sentido geral do texto. Os resultados da análise do material textual mostram que as bases miméticas do agir social levam à apropriação do mundo e constituição do sujeito, tendo o ritual como constituição do sujeito e noção de pertencimento à comunidade. As funções do ritual na educação envolvem: a) relações sociais, realidade social, relações de poder e contexto; b) performance e práticas corporais; c) tempo e espaço, repetição e sequencialidade; d) alteridade, sincronicidade, diacronia e mudanças sociais e culturais.

A conclusão mostra que, por meio da mimesis, a comunidade se exprime, se mantém, se transforma auxiliada pelos rituais; logo, os modos de expressão são captados, compreendidos e transmitidos, por meio do corpo, gestos e performance. $\mathrm{Na}$ construção da relação entre mimesis e ritual, é possível considerar que os rituais moldam as transições entre os campos da socialização e das instituições e facilitam a aprendizagem social e cultural. Em virtude da sua performatividade, os processos educacionais funcionam como rituais e ritualizações em outros campos da ação social. Esses pontos levam a refletir sobre a importância do ritual no processo mimético e na educação, tendo em vista, os poucos trabalhos sobre mimesis na perspectiva da antropologia da educação que se tem desenvolvido sobre a dinamicidade e a transformação na educação. 


\section{MIMESIS: A HISTORICIDADE DO PROCESSO MIMÉTICO}

Mimesis é um conceito multifacetado e está presente em diversas áreas do conhecimento. A princípio, significa imitação advinda diretamente do aspecto físico, dos atos, ou seja, a reprodução de um quadro ou de uma imagem de uma pessoa ou de uma coisa em sua forma material. Em seguida, passou a significar "fazer uma representação de alguma coisa" e, atualmente, exprime apropriação do mundo.

Na obra A República, Platão (2011) explica que a dimensão educativa da mimesis consiste em representar fenômenos, por isso recai sobre o sentido de imitar, representar e expressar para criar semelhanças no sentido estético. Nesse caso, o objetivo do processo mimético consiste em criar ações-modelo ou homem-modelo para executar suas tarefas. Para Aristóteles (1965), a mimesis é a força constitutiva de um mundo estético e autônomo da aparência e limitado à arte, poesia e estética. No domínio da arte, trata-se de imitar a natura naturans, isto é, imitar a força da natureza, porque imitar significa produzir imagem. Em Platão e Aristóteles os fenômenos nunca foram abordados na perspectiva social.

No período moderno, mais especificamente no século 17, o princípio da mimesis estava relacionado à representação do poder. Os artistas foram evocados para realizar a representação do retrato do rei, do seu ser simbólico e da representação de sua essência. As narrativas da imagem do rei sempre o mostraram como o homem mais poderoso do mundo. A mimesis, no século 18, é usada como instrumento de poder, no qual a burguesia exige o comando social e participa na formação do bom gosto e dos sentimentos nobres. Essa formação acontece por meio do teatro, que oferece aos espectadores modelos de autorrepresentação e interpretações comportamentais.

Em decorrência da crítica à repressão das relações miméticas que sempre estiveram ligadas à escrita, à arte e à linguagem, Benjamim $(1987)^{2}$, no século 20, redescobre e redefine o conceito de mimesis. Esse conceito é redescoberto como um bem humano e como uma capacidade antropológica fundamental, pois é o encontro da criança com o seu meio e correspondências não sensíveis entre objetos, significados e passado. Wulf e Zirfas (2004), no entanto, ao criticar Benjamim, explica que o autor não mostrou como a criança se apropria do mundo por intermédio de gestos e performance.

Por outro lado, Adorno e Horkheimer (1985) esboçam um tipo de fundamentação antropológica de uso dos símbolos por meio do processo mimético. Em Dialética do Esclarecimento, o conceito de mimesis é utilizado para descrever a ambiguidade da relação do homem com a natureza, o externo e o interno para permitir o surgimento da libertação da dominação. As obras de arte representam, na modernidade, uma possível revisão ou neutralização do domínio da natureza. A mimesis estética forma um tipo de molde que reflete as relações externas da sociedade, as assimetrias, as cisões, rupturas e divisões da práxis social.

O título original da obra é Berliner Kindheit um neunzehnhundert, publicada, postumamente, em 1950. 
A Mimesis é como um elemento da organização social e fundamento das formações culturais.

As ações miméticas são constituídas por movimentos corpóreos que incluem as mais diversas formas de interação, comunicação e linguagem (verbais ou não) [...]. Pode-se afirmar que certas ações sociais são miméticas quando se constituem de movimentos que possuem correspondência com outros movimentos, isto é, podem ser reconhecidos em atividades da vida cotidiana; quando podem ser tratadas como apresentações corporais que possuem aspecto de representação [...], o que significa reconhecer o caráter performático e teatral. As ações miméticas são tanto ações independentes, que podem ser compreendidas em si mesmas, como também possuem correspondências com outros mundos [...] (GRIGOROWITSCHS, 2010, p. 232).

O intermédio da apropriação de certos elementos da vida cotidiana e sua transformação acontece por meio das faculdades miméticas dos processos sociais que permitem ao ser humano estar no mundo corporeamente, dando forma às interações. Esse intermédio envolve transformação, estando presente na reprodução dos elementos da vida cotidiana e na sua transformação, recriação, recontextualização (GEBAUER; WULF, 1998).

\section{RITUAL: Conceituação}

A vida social cotidiana é sempre marcada por rituais, ao contrário de muitos pensarem que esteja relacionada às sociedades históricas ou à vida na corte europeia ou às sociedades indígenas (PEIRANO, 2003). De acordo com o dicionário Houaiss, Ritual: 1) litur.cat livro que contém os ritos estabelecidos por uma religião e a forma de executar as cerimônias e os serviços divinos, 2) p.met. o culto religioso; cerimônia, liturgia; 3) p.met. conjunto de atos e práticas próprias de uma cerimônia ritualística; 4) p.ext. a etiqueta, o conjunto das regras socialmente estabelecidas que devem ser observadas em qualquer ato solene; cerimonial [prática]; 5) adj. relativo ou pertencente a rito; 6) adj. conforme a um rito, que se assemelha a um rito [paciência], [cuidado] (HOUAISS, 2001, p. 2.463).

$\mathrm{O}$ antropólogo Tambiah apresenta a seguinte definição de ritual:

O ritual é um sistema cultural de comunicação simbólica. Ele é constituído de seqüências ordenadas e padronizadas de palavras e atos, em geral expressos por múltiplos meios. Estas seqüências têm conteúdo e arranjo caracterizados por graus variados de formalidade (convencionalidade), estereotipia (rigidez), condensação (fusão) e redundância (repetição). A ação ritual nos seus traços constitutivos pode ser vista como "performativa" em três sentidos: 1) no sentido pelo qual dizer é também fazer alguma coisa como um ato convencional [como quando se diz "sim" à pergunta do padre em um casamento]; 2) no sentido pelo qual os participantes experimentam intensamente uma perfomance que utiliza vários meios de comunicação [um exemplo seria o nosso carnaval] e 3), finalmente, no sentido de valores sendo indeferidos e criados pelos atores durante a performance [por exemplo, quando identificamos como "Brasil" o time de futebol campeão do mundo] (apud PEIRANO, 2003, p. 11). 
O ritual, então, envolve sequencialidade, convenção, performance e valores, e, por ser um sistema cultural de comunicação simbólica, não é algo fossilizado, imutável e definitivo. $O$ ritual acontece em concomitância de sujeitos, tempo e espaço, assim como necessita de objetivos, procedimentos, técnicas, instrumentos e objetos. Os propósitos dos rituais são muito variados e podem incluir obrigações religiosas ou ideais, satisfação de necessidades espirituais ou emocionais dos praticantes, fortalecimento de laços sociais, demonstração de respeito ou submissão, aprovação ou, às vezes, apenas o prazer do ritual em si (DAMATTA, 1997). Podem incluir, conforme Douglas (1991), vários ritos de adoração e sacramentos de religiões organizadas e cultos, mas, também, os ritos de passagem de certas sociedades, como coroações, posses presidenciais, casamentos e funerais, eventos esportivos e outros.

A antropologia contemporânea, como explicita Wulf e Zirfas (2004), apresenta uma definição mais ligada à performance e aos gestos. Sendo assim, o ritual é um conjunto de gestos, palavras e formalidades, geralmente imbuídos de um valor simbólico, cuja performance é usualmente prescrita e codificada por uma religião ou pelas tradições da comunidade.

De acordo com Wulf e Zirfas (2004), os rituais são ações sem palavras e expressas por gestos, e são movimentos corporais com começo e fim. São processos corporais codificados por símbolos que criam realidades sociais, as interpretam, as mantêm e as modificam. Os rituais ocorrem no espaço, são realizados por grupos, obedecem normas que são inscritas no corpo por meio do comportamento ritual. As ritualizações, enquanto mise en scène simbólicas, são diferentes das apresentações teatrais, da ópera, porque elas são especialmente realizadas por e pelos indivíduos presentes.

Wulf e Zirfas (2004), em uma sistematização do ritual, mostram que existem quatro abordagens da pesquisa em ritual. A primeira apresenta pesquisas sobre rituais ligadas à religião, mito e cultura, cujos principais expoentes são: Herbert Spencer, James Frazer, Rudolf Otto e Mircea Eliade. A segunda demonstra as estruturas e valores da sociedade presentes nos rituais, e seus principais autores são: Emile Dürkheim, Arnold van Gennep e Victor Turner. A terceira linha de pesquisa mostra que os rituais são lidos como texto e o objetivo é a decodificação da dinâmica cultural e social da sociedade, como demonstrado nas obras de Clifford Geertz e Marshall Sahlins. A pesquisa mais recente sobre rituais começa com a atenção dada à importância dos rituais, da simbolização cultural e da comunicação cultural, demonstrada por Catherine Bell, Ronald Grimes, Victor Turner e Hans-Georg Soeffner. Por último, a quarta linha de pesquisa, que destaca o lado prático e o encenado, performativo dos rituais, e o foco desta abordagem são as formas de ações rituais que permitem às comunidades gerar, restituir e editar suas diferenças. Os principais autores são: Stanley Tambiah, Richard Schechner, Pierre Bourdieu e Christoph Wulf.

\section{A MIMESIS E A EDUCAÇÃO}

Gebauer e Wulf (2004) mostram que a relação entre mimesis e educação tem papel central na gênese da educação do ser humano e, por isso, contribui para a formação do ser humano. Inicialmente, a relação entre mimesis e educação é apresentada na obra A República, de Platão. O ponto de partida de Platão diz respeito à imprescindível 
necessidade do homem em manter relação com o mundo e consigo mesmo. Essa relação ocorre, particularmente, na infância, e, também, na adolescência e na vida adulta, de modo que os efeitos pedagógicos da mimesis ocorrem entre os vivos e nas formas imaginárias.

Por causa dos efeitos intensos da mimesis na formação do mundo de ideias da juventude, ela deve ser mantida sob controle, pois as imagens e os padrões absorvidos de forma mimética no mundo de ideias da juventude provocam efeitos nas ações dos jovens. Por esta razão, somente pessoas exemplares devem ser postas diante da juventude, pois de exemplos ruins só podem advir conseqüências negativas que provocam ações indesejadas (GEBAUER; WULF, 2004, p. 83).

Platão desenvolveu uma crítica poética, musical e à cultura em geral, no sentido de alertar para a sua má influência na formação dos jovens. Enquanto isso, no livro III o valor pedagógico da mimesis é ressaltado, porque Platão se livra de questões como bem e verdadeiro e coloca a mimesis como produção da aparência de um fenômeno diante do fundamento da doutrina das ideias, desenvolvida no mito da caverna.

Girard (1990), então, apresenta a perspectiva ampliada para os efeitos sociais e pedagógicos e coloca os elementos miméticos como importantes para os processos da vida e para as constelações sociais e educativas. Segundo Girard (1990), nas constelações miméticas há o mecanismo invisível, que é processado da seguinte maneira:

A criança comporta-se mimeticamente diante do adulto que se tornou aquilo que ela ainda vai se tornar, isto é, a criança anseia, também com o auxílio do adulto, a tornar-se aquilo que este já é. Ao mesmo tempo, nem o adulto, nem a criança podem suportar o tornar-se semelhante e a perda da diferença, que lhes assegura as correspondentes singularidades. Por esta razão, há uma cisão na relação entre o desejo de tornar-se semelhante e o desejo de diferenciar-se e ser singular. Portanto, mimesis e desejo estão intimamente ligados, visto assim, todo desejo é mimético (p. 123).

$\mathrm{Na}$ formação mimética da criança existem diferenças e o desejo de tornar-se semelhante ao outro. Para Gebauer e Wulf (2004), o outro produz a criança; logo, a imitação que a criança faz do outro é porque ela ainda não sabe a diferença entre si e o outro, não tem autopercepção, tampouco sentimento de si, e deixa-se absorver por inteira pelo outro e pelos objetos. Nesse caso, o adulto tem relevância.

$\mathrm{O}$ adulto mostra à criança que ela está à procura de si própria, e percebe uma deficiência, quem é ela e quem está em condição de fazê-la tal, pois a criança não tem em si a possibilidade de se encontrar. $O$ adulto vai mostrá-lo como ela chegará a si. O caminho é a mimesis do desejo do adulto, através do qual o próprio desejo será desenvolvido (GEBAUER, WULF, 2004, p. 88).

Nessa procura de si, o adulto mostra o caminho para a criança se encontrar; caminho em que é formada uma relação social que leva a uma representação do outro na criança e na constituição do sujeito. Os autores explicam que os pais e educadores estão ajudando a criança a se constituir como um ser autônomo quando transmitem a ela a experiência de que eles não sabem e não acham que sabem quem ou o que é a criança na verdade. Desse modo, a mimesis lança uma ponte ao Outro, e o objetivo é uma realização da expressão do Outro que não o relacione a Outro fora dele mesmo. 


\section{OS RITUAIS NA EDUCAÇÃO}

Os rituais criam as transições entre os campos da socialização e as instituições; por isso, desempenham um papel central na pedagogia, educação e socialização das crianças, porque estruturam a sua vida e apoiam sua integração em uma ordem social, assim como facilitam a aprendizagem social e cultural (WULF, 2012).

Em virtude da sua performatividade, os processos educacionais funcionam como rituais e ritualizações em outros campos da ação social. A forma como as crianças executam seu comportamento, seja sozinha ou em conjunto com adultos, pode ser vista como a performatividade de suas ações. Aspectos importantes da aprendizagem cultural ocorrem por meio de processos miméticos. Neste, imagens, esquemas, expectativas dos outros, situações sociais, ocorrências e ações são incorporados ao mundo das imagens mentais de um indivíduo. Esse conhecimento prático permite que as crianças aprendam e ajam juntas, a viver e a ser.

Em Towards a Historical Cultural Anthropology of Education: The Berlin Ritual Stu$d y$ são descritas as categorias centrais dos rituais na educação (WULF, 2012, p. 9-10): 1) Rituais e ritualizações desempenham um papel central na educação, pois estruturam as vidas das crianças e ajudam na sua integração em uma ordem social; 2. O caráter performativo das práticas pedagógicas e sociais refere-se à sua corporeidade; 3 ) Processos miméticos facilitam a incorporação de imagens, esquemas e imaginações de outras pessoas, situações sociais, eventos e ações e os integram em um mundo mental de imagens; 4) A educação possui tarefa intercultural, para a qual rituais e ritualizações, gestos pedagógicos e sociais, a performatividade de práticas sociais, assim como formas miméticas de aprendizagem, desempenham um papel importante; 5) Etnografia e métodos qualitativos, como observação participante, observação baseada em vídeo, videoperformance e fotoanálise, bem como entrevistas e discussões em grupo, são úteis para a investigação de rituais e ritualizações, da performatividade de práticas pedagógicas, assim como de processos de educação miméticos e interculturais.

\section{METODOLOGIA}

Este trabalho faz análise e reflexão de material textual sobre mimesis e ritual. A análise do material acontece por meio da Análise de Conteúdo Hermenêutica, mixed de métodos, segundo Vieira e Queiroz (2017) e Vieira (2017, 2018). O método selecionado consiste em analisar, demonstrar e refletir o material textual das obras selecionadas. Três obras foram selecionadas: 1) Mimese na cultura: agir social, rituais e jogos, produções estéticas, 2) Towards a Historical Cultural Anthropology of Education: The Berlin Ritual Study e 3) Performative Welten. Einführung in die historischen, systematischen und methodischen Dimensionen des Rituals. Este corpus foi selecionado para análise, tendo como base os seguintes critérios: obras de relevância de autoria de Christoph Wulf, relação com a área da Antropologia da Educação Histórico-Cultural Alemã e em cujo título conste as palavras mimesis e ritual. 
De todo o material, foi feita a análise do sentido geral do texto. Essa compreende uma análise mais aberta do conteúdo, sem interferências de pré-codificação. Nesse sentido, a Hermenêutica é utilizada para a análise do movimento circular, aliando as dimensões objetiva e subjetiva da pesquisa, de modo a considerar a interpretação, a compreensão e a reflexão (VIEIRA; QUEIROZ, 2017).

\section{ANÁLISE E RESULTADOS}

A análise do material textual mostra as bases miméticas do agir social e a apropriação de mundo por meio do ritual e as funções do ritual na educação.

\section{As bases miméticas do agir social e apropriação de mundo por meio do ritual}

As bases miméticas do agir social levam à apropriação do mundo e à constituição do sujeito, tendo o ritual como constituição do sujeito e noção de pertencimento à comunidade, segundo a obra Mimese na cultura: agir social, rituais e jogos, produções estéticas, de Gebauer e Wulf (2014).

$\mathrm{Na}$ apropriação de mundo e constituição do sujeito, a criança vive o mundo de forma mimética, ou seja, a criança produz semelhanças entre si e o mundo exterior. Assim, ela lê o mundo e cria correspondências neste processo.

[...] ela torna-se um moinho de vento quando estica os braços e os faz rodar, produzindo ao mesmo tempo com sua boca o vento necessário para isso. As suas experiências crescem através disso: a criança compreende como o vento impulsiona o moinho; ela vivencia algo do poder do vento e do poder do uso humano da natureza; ela alcança a fascinação da produtividade humana [...] (GEBAUER; WULF, 2004, p. 141).

Isso significa que a criança é capaz de transformar suas experiências no ato mimético de transformação em um moinho de vento. A criança vivencia seu corpo como instrumento de representação e expressão, identifica-se com o seu corpo e alcança reconhecimento social. Gebauer e Wulf (2004) explicam que o ser semelhante e o tornar-se semelhante representam momentos centrais no desenvolvimento infantil e na sua relação com o mundo, com a linguagem e consigo próprio.

No ritual como constituição do sujeito e pertencimento da comunidade, os processos da mimesis social permitem a ligação do mundo interior com o mundo exterior, no qual desenvolve o seu significado para o social, a educação e socialização. Os rituais também dependem dessa forma de função da mimesis, na medida em que as pessoas participam na família, escola, comunidade e política de rituais, se constituem como sujeitos e criam noção de pertencimento à comunidade. É por meio do agir e do comportar-se no ritual que são registradas as normas sociais nos corpos dentro de um contexto histórico e cultural.

Os rituais podem ser entendidos como fenômenos da mimesis social por meio de encenações corporais, sensíveis e imaginárias de relações pedagógicas, quando são encenadas formas de agir e de se comportar aceitas coletivamente. Por exemplo, a criança, quando chega à escola e passa pelo portão, logo vai formar a fila para entrar na sala de aula. Ali, ela cria à noção de pertencimento do mundo escolar, encenando corporeamente a ação social de formar fila. De um lado, repetem arranjos cênicos, ordens e 
estruturas no momento em que se dirigem para o pátio para formar fila e, de outro, são espontâneas e articulam forças inovadoras, no momento em que sentam no chão enquanto aguardam o sinal para dirigir-se à sala de aula. Segundo Gebauer e Wulf (2004), o ritual pode ser entendido como uma dimensão do social, a qual forma o sujeito, criança, para o mundo escolar ou cotidiano e para a o seu pertencimento na comunidade.

\section{As funções do ritual na educação}

O ritual preenche funções centrais na educação e nas atividades rituais por meio das práticas ritualizadas que acontecem na performance e no lado prático e corporal. As obras Mundos performativos. Introdução às dimensões históricas, sistemáticas e metodológicas do ritual e Rumo a uma antropologia histórica da educação: o estudo do ritual de Berlim ${ }^{3}$, mostram que o ritual possui 12 funções centrais na educação, que envolvem: a) relações sociais, realidade social, relações de poder e contexto; b) performance e práticas corporais; c) tempo e espaço, repetição e sequencialidade; d) alteridade, sincronicidade, diacronia e mudanças sociais e culturais.

a) Relações sociais, realidade social, relações de poder e contexto:

- os rituais elaboram relações sociais na educação, cujo conteúdo simbólico e performativo cria e estabiliza sua identidade e estruturas de ordem e garante sentimento de segurança. As comunidades educacionais e sociais são formadas em práticas ritualizadas que são a causa, a ação e o efeito dos rituais, possibilitando a familiaridade na vida cotidiana;

- uma nova realidade social e educacional é criada durante o arranjo performativo dos rituais e faz com que algo se torne visível;

- nas performances dos rituais, as hierarquias sociais e estruturas de poder são encenadas e colocadas em contexto e a repetição do ritual é uma das estratégias sociais mais eficazes para estabelecer e assegurar estruturas de poder na educação;

- os rituais têm sido substituídos por rituais menores que se relacionam com áreas específicas da vida e que mudam de acordo com a instituição e o contexto. Crianças e adultos precisam de rituais e atividades rituais para a criação performativa de suas comunidades e são indispensáveis.

\section{b) Performance e práticas corporais:}

- no arranjo e encenação performativa dos rituais na educação, o caráter performativo produz seu efeito pleno, podendo assumir muitas formas;

- os corpos dos participantes estão implicitamente envolvidos na encenação e realização dos rituais na educação, porque os movimentos e práticas dos corpos requerem nossa atenção. As crianças, por exemplo, precisam experimentar o fluxo de energias entre as pessoas.

3 Título original: Performative Welten. Einführung in die historischen, systematischen und methodischen Dimensionen des Rituals e Towards a Historical Cultural Anthropology of Education: The Berlin Ritual Study. 


\section{c) Tempo e espaço, repetição e sequencialidade:}

- a articulação do espaço real, virtual, simbólico e imaginário com os movimentos corporais dos participantes desempenha um papel importante no desenvolvimento das atividades rituais;

- os rituais estão ligados ao tempo e ao espaço e na reafirmação da ordem e da transformação por meio da repetição, servindo para garantir a presença da comunidade e para reafirmar sua ordem e potencial de transformação por intermédio dessa repetição;

- para acontecer a atividade ritual existe uma sequência que está intimamente ligada à adesão às regras, que seguem uma ordem cronológica e são importantes para a vida da criança.

d) Alteridade, sincronicidade e diacronia e mudanças sociais e culturais:

- os rituais são importantes para a interação entre crianças de diferentes etnias e desempenham papel relevante no que diz respeito às alteridades e no contexto multicultural das escolas;

- para o sucesso das práticas rituais na educação, a sincronia e a diacronia são vitais. A dimensão sincrônica dos processos miméticos relaciona-se com a importância dos processos miméticos na execução real dos rituais na educação; a dimensão diacrônica relaciona-se com os aspectos históricos dos rituais;

- no desenvolvimento das habilidades necessárias para os rituais e a evolução da participação em atividades, os rituais na educação e socialização permitem a aprendizagem do conhecimento prático necessário para as práticas rituais. Eles criam continuidade e permitem mudanças históricas e culturais. Os rituais na educação não são estáticos; são dinâmicos, e têm potencial para instituir ou impedir mudanças sociais e culturais.

Em Rituale als performative Handlungen und die mimetische Erzeugung des Sozialen, Wulf (2015) explica que os rituais criam sentimentos de pertencimento e produzem comunidades, de modo que moldam as transições sociais e transmitem conhecimento prático. O seu impacto social aumenta em razão do caráter performativo combinado com sua encenação e desempenho. No processo mimético, isto é, nos processos de imitação criativa, é adquirido conhecimento ritual prático baseado no corpo. Isso permite que as pessoas ajam adequadamente nas instituições.

\section{DISCUSSÃO: Fenômenos Sociais e Culturais na Educação}

A análise mostra a apropriação do mundo e a constituição do sujeito, tendo o ritual como constituição do sujeito e noção de pertencimento à comunidade que ocorrem pelo agir social mimético, envolvendo as funções do ritual.

A conceituação atual de ritual e os estudos de mimesis, bem como a sua relação, no entanto, implicam pensar no seguinte questionamento: Como se constitui a relação do processo mimético com o ritual enquanto fenômenos da mimesis social e cultural? Os estudos de Wulf (2005) apresentam que os rituais são fenômenos de mimesis social e cultural, de forma que abrem novas perspectivas para a compreensão 
dos rituais, das ritualizações e do comportamento ritual. Por exemplo, ao considerar a mise en scène corporal e imaginária das relações sociais, é importante compreender a comunidade não como uma estrutura social regida por normas e regras fixas, mas como uma comunidade que se articula e se desenvolve de forma espontânea, por meio de rituais e ritualizações, levando à transitoriedade e às mudanças da sociedade.

Para Wulf (2005), os ritos e rituais são fenômenos extremamente diversificados e dizem muito sobre o ser humano; logo, falar em vida social é falar em ritualização, porque, constantemente, o ser humano busca a reelaboração do imaginário, manifestando-o de diferentes formas e com rituais diversos, a fim de manter a identidade e a cultura do local em que está inserido. Por meio da capacidade de produzir imagens e signos, o ser humano consegue determinar e fixar o particular em sua consciência em meio à sucessão de fenômenos sociais e culturais que se seguem no tempo.

Um novo espaço abre-se para o grupo social com os diferentes fenômenos sociais e culturais enfocando os processos de mudanças no decorrer da vida dos indivíduos. Esses fenômenos ampliam alcance do processo de transmissão social e cultural, essencial para a perpetuação dos grupos e da sociedade. Os rituais, quando estruturados e organizados, legitimam as posições dos indivíduos e grupos e reconhecem os valores morais e posições de mundo.

Segundo Wulf (2005), por meio da mimesis a comunidade se exprime, se mantém, se transforma, auxiliada pelos rituais; logo, os modos de expressão são captados, compreendidos e transmitidos. Os rituais são parte importante do domínio da pesquisa em antropologia educacional histórico-cultural alemã.

Gebauer e Wulf (2004) ressaltam que as relações entre dois mundos, interno e externo, são pontos centrais da mimesis social. O primeiro mundo é tomado ou postulado como existente, em que o eu é considerado, assim como a parte interna do ser humano. O segundo mundo, mimético, existe em um meio de comunicação real, sensível e corporal. Ele é gesto, som, escrita, execução, pintura, ação representativa, ritual, etc. Esse mundo é criado em um meio de comunicação mediante uma ação social em que ocorre a apropriação do mundo e a constituição do sujeito por intermédio de práticas ritualísticas.

Por isso, na construção da relação entre mimesis e ritual é possível considerar que os rituais moldam as transições entre os campos da socialização e das instituições e facilitam a aprendizagem social e cultural. Em virtude da sua performatividade, os processos educacionais funcionam como rituais e ritualizações em outros campos da ação social. A forma como as crianças executam seu comportamento, seja sozinha ou em conjunto com adultos, pode ser vista como a performatividade de suas ações. Aspectos importantes da aprendizagem cultural ocorrem por meio de processos miméticos. Neste, imagens, esquemas, expectativas dos outros, situações sociais, ocorrências e ações são incorporados ao mundo das imagens mentais de um indivíduo. Esse conhecimento prático permite que as crianças aprendam e ajam juntas, a viver e a ser. 


\section{CONSIDERAÇÕES FINAIS}

A mimesis e o ritual como pesquisa são relevantes para a educação porque consideram elementos da vida cotidiana e seus processos sociais e culturais, promovendo a transformação e pertencimento do ser humano no mundo. A teoria apresentada sobre mimesis e ritual mostra que a abordagem atual é uma condição fundamental para compreender a existência, reprodução e produção da vida humana. A mimesis como capacidade humana criativa de ação social, saber de ação prática e aprendizado social e cultural e o ritual como dimensão do social, a qual forma o sujeito, criança, para o mundo escolar ou cotidiano e para a o seu pertencimento na comunidade.

A análise, na qual utiliza-se a análise de conteúdo hermenêutica, foi fundamental para a compreensão das bases miméticas do agir social e apropriação de mundo por meio do ritual, além de auxiliar a compreender as funções do ritual na educação. A constituição do sujeito por meio do processo mimético do ritual faz com que a criança leia o seu mundo, faça correspondência e crie semelhanças, de modo que se sinta pertencente à comunidade em que vive. Os rituais são fenômenos de mimesis social e cultural em que se considera a transitoriedade e as mudanças da sociedade.

Esse artigo faz surgir novos questionamentos: Como pesquisar o ritual e o processo mimético na cultura e sociedade brasileira? Quais métodos e procedimentos são necessários para investigar tais relações? Como se configuraria a pesquisa sobre mimesis e ritual na área da educação no Brasil? Como considerar os corpos e gestos dos participantes no ritual na educação? O que o arranjo desses corpos e gestos no ritual nos diz sobre a comunidade, os indivíduos e sua cultura? São essas questões que nos levam a refletir sobre a importância do ritual no processo mimético e na educação, tendo em vista os poucos trabalhos sobre mimesis na perspectiva da antropologia da educação que se tem desenvolvido sobre a dinamicidade e a transformação na educação.

\section{REFERÊNCIAS}

ADORNO, T. W.; HORKHEIMER, M. Dialética do esclarecimento. Rio de Janeiro: Zahar, 1985.

ARISTÓTELES. The Poetics. London: W. Heinemann, 1965.

BENJAMIN, W. Infância em Berlim por volta de 1900 [1932-1933]. São Paulo: Brasiliense, 1987.

DAMATTA, Roberto. Carnavais, malandros e heróis. Rio de Janeiro: Rocco, 1997.

DOUGLAS, Mary. Pureza e perigo. Lisboa, PT: Edições 70, 1991.

GEBAUER, G.; WULF, C. Spiel, Ritual, Geste. Mimetische Grundlagen sozialen Handelns. Hamburg: Reinbek, 1998.

GEBAUER, G.; WULF, C. Mimese na cultura: agir social, rituais e jogos, produções estéticas. Tradução Eduardo Triandopolis. São Paulo: Annablume, 2004.

GIRARD, R. A violência e o sagrado. São Paulo: Editora Unesp; Paz e Terra, 1990.

GRIGOROWITSCHS, T. Jogo, mimese e infância: o papel do jogar infantil nos processos de construção do self. Revista Brasileira de Educação, v. 15, n. 44, maio/ago. 2010.

HOUAISS, Antonio. Dicionário Houaiss da Língua Portuguesa. Rio de Janeiro: Objetiva, 2001.

PLATÃO. A república. Rio de Janeiro: Nova Fronteira, 2011.

PEIRANO, Mariza. Rituais ontem e hoje. Rio de Janeiro: Jorge Zahar Ed., 2003.

VIEIRA, Karina Augusta Limonta. Análise de Conteúdo Hermenêutica. In: VIEIRA, Karina Augusta Limonta. Antropologia da Educação: levantamento, análise e reflexão no Brasil. Curitiba: CRV, 2017.

VIEIRA, Karina Augusta Limonta. Análise de conteúdo hermenêutica na educação. @rquivo Brasileiro de Educação, Belo Horizonte, v. 6, n. 13, jan./abr. 2018. 
VIEIRA, Karina Limonta; QUEIROZ, Gustavo Morais. Hermeneutic content analysis: a method of textual analysis. International Journal of Business Marketing and Management (IJBMM), v. 2, n. 8, p. 8-15, 2017. WULF, C. Mimesis social. In: WULF, C. Antropologia da educação. Campinas: Alínea, 2005.

WULF, C. Towards a Historical Cultural Anthropology of Education: The Berlin Ritual Study. In: ANDERSON-LEVITT, K. (ed.). Anthropologies of Education. A global Guide to Ethnographic Studies of Learning and Schooling. New York; Oxford: Berghahn Books, 2012.

WULF, C. Homo Pictor. Imaginação, ritual e aprendizado mimético no mundo globalizado. São Paulo: Hedra, 2013.

WULF, C. As bases miméticas do aprendizado cultural. In: Antropologia. História, Cultura, Filosofia. São Paulo: Anablume, 2014a.

WULF, C. Mimesis. In: WULF, C.; ZIRFAS, J. (org.). Handbuch Pädagogische Anthropologie. Berlin: Springer, 2014b.

WULF, C. Rituale als performative Handlungen und die mimetische Erzeugung des Sozialen. In: GUGUTZER, Robert; STAACK, Michael (orgs.). Körper und Ritual. Sozial- und kulturwissenschaftliche Zugänge und Analysen. Berlin: Springer, 2015.

WULF, C. Aprendizagem cultural e mimese: jogos, rituais e gestos. Revista Brasileira de Educação, v. 21, n. 66, p. 553-568, jul./set. 2016.

WULF, C.; ZIRFAS, J. Performative Welten. Einführung in die historischen, systematischen und methodischen Dimensionen des Rituals. In: WULF, C. Die Kultur des Rituals Inszenierungen, Praktiken, Symbole. München: Wilhelm Fink Verlag, 2004. 